\title{
Factors Influencing Usage Intentions Towards a Self-service Kiosk with Biometric Authentication
}

\author{
Gabriele Obermeier \\ University of Applied Sciences \\ Upper Austria \\ gabriele.obermeier@fh-steyr.at
}

\author{
Jasmin Klingersberger \\ University of Applied Sciences \\ Upper Austria \\ jasmin.klingersberger@students.fh-
}

\author{
Andreas Auinger \\ University of Applied Sciences \\ Upper Austria \\ andreas.auinger@fh-steyr.at
}

\section{steyr.at}

\begin{abstract}
Self-service technologies have developed as helpful tools in our everyday lives while constantly being adapted to meet new challenges and requirements in today's world. This study explores the factors influencing usage intentions towards a selfservice kiosk with biometric authentication in a retail context. A quantitative study with 28 participants was conducted in a laboratory environment. Participants were asked to purchase a SIM card at a self-service kiosk. The findings revealed that convenience and relative advantage had a strong impact on usage intention. In contrast, functionality and security concerns towards biometric authentication showed no significant effects. In addition, the results indicate that usage intention affected positive word of mouth. Further analysis revealed that usage intention mediated the relationship between the significant influence factors (i.e., convenience, relative advantage) and word of mouth.
\end{abstract}

\section{Introduction}

"Iris scan commencing. Identity validated. Welcome, commander." When we watched the Minority Report in 2002 [1], who would have guessed that Tom Cruise's biometric authentication would be part of our everyday lives 15 years later. In 2017, Apple Inc. introduced their novel iPhone model with the "Face-ID" feature enabling users to unlock their smartphone or conduct payments with the device [2].

Biometric technologies rely on the "who you are" (i.e., physiological) and "what you do" (i.e., behavioral) concepts. Driven by increasing fraudulent activities and identity thefts in the digitalized economy, a recent market report of BusinessWire [3] expects the market for identity verification to increase from USD 7.6 billion in 2020 to USD 15.8 billion in 2025 .

One practical example can be found in the travel sector. Specifically, numerous airports offer self- service biometric authentication kiosks for check-in and immigration clearance processes [4], [5]. On the one hand, the facial biometric authentication method provides a secure identification of the individual, matching the real-time camera shot with the picture on the identification (ID) card. On the other hand, selfservice technology provides several benefits, such as a contact-less, quick, and convenient procedure [6].

Since Meuter et al.'s [7] well-known study explaining customer satisfaction with self-service technologies in 2000, these systems have gained immense attention in academic research [8] and are still intensively discussed, especially in the retail sector (e.g., [9], [10]). Retailers constantly identify new technological trends that could potentially improve the customer's experience [11]. From the retailer's perspective, self-service technologies can help to reduce labor costs, improve productivity and enhance the quality of customer service quality [12], [13]. The most commonly known self-service technologies can be found in the banking sector (i.e. ATM) [6]. Kiosk or terminal systems are specific types of self-service technologies, described as interactive free-standing computer systems that enable users to conduct a purchase or receive a service without the presence or direct involvement of service employees [14]. In addition, self-service kiosks can increase customer touchpoints, provide information, and enhance customer engagement [14].

As prior literature states, some types of selfservice kiosks, such as those with biometric authentication, are rarely investigated in current research [15]. Empirical studies are needed to examine whether customers feel secure using a biometric authentication system and whether they would intend to use it [16]. Therefore, identifying factors that influence usage behavior towards a self-service retail technology promises to further increase the predictability of customer behavior in the changing B2C technological retail environment. 
Consequently, this paper a) investigates factors affecting usage intentions towards a self-service kiosk and b) how these intentions influence positive word-ofmouth (WOM). To address these research goals, we first provide a background on self-service technology research and biometric authentication. Next, we propose our research model and hypothesis, followed by an explanation of the study's methodology. After that, the results of the regression and mediation analyses are presented and discussed, followed by the conclusion.

\section{Background}

\subsection{Research on self-service technology}

Self-service technologies refer to "technological interfaces that enable customers to produce a service independent of direct service employee involvement" (p.50) [7]. Literature provides a plethora of studies investigating users' perception and adoption behavior towards self-service technology, especially by extending well-known models such as the technology acceptance model (TAM) [8]. The huge amount of studies on self-service technologies might result from the various fields where these systems can be applied, such as banking [17], governmental and public services [18], libraries [19], healthcare [20], hospitality [21], to name a few.

According to a recent literature review by Vakulenko et al. [15], self-service kiosks can provide customer value throughout a cycle of recurring stages of pre and post-experience as well as during the actual interaction stage. The customers' pre-experience stage refers to their demographic attributes, individual expectations, etc., and defines their attitude to using the self-service kiosk [14], [22]. The customer's actual interaction with the self-service kiosk will affect their post-experience behavior, such as a change in intention to use and WOM [23], [24]. Thus, customer value appears at all three stages [15].

Hsu et al. [25] suggest categorizing self-service technology research into three streams: first, examining determinants of self-service technology adoption. Second, the value co-creation from selfservice technology interaction. Third, the pitfalls of using self-service technology.

With regard to its aim, which is identifying factors that affect usage intentions towards a self-service kiosk with biometric authentication, this study can be classified within Hsu et al.'s [25] first category of research streams. With regard to Vakulenko et al.'s [15] value cycle, this study is concerned with the actual interaction and post-experience behavior.

\subsection{Biometric authentication}

The combination of a person's eye color, the size of their nose and mouth, and the little scar on their eyebrow are unique facial features, so-called "eigenfaces", that contribute to a person's biometric identity [26]. Per definition, biometric identification is a method to verify a person's unique physical (e.g., face, iris, or fingerprint scans) or behavioral traits (e.g., voice recognition, handwritten signatures) to automatically authenticate their access to digital devices or a specific set of services [27], [28].

The main purpose of biometric authentication procedures is to confirm the presence of the legitimate person [29] while improving and protecting the user's security and privacy [30]. In contrast, conventional security methods such as credit cards, passwords, or PINs bear the risk of data breaches or can also be easily lost and forgotten by the owner [27].

One specific method among biometric technologies is the facial biometric authentication method which usually involves several steps: First, the person's face is captured using a camera and further matched against a scan of the person's ID card [31]. Finally, the system compares the physical traits and verifies the person's identity [31].

For the purpose of developing a customer acceptance model for biometric authentication systems, Kanak and Sogukpinar [30] developed the BioTAM. In contrast to the original TAM [32], the BioTAM investigates the influence of trust on perceived usefulness and perceived ease of use, affecting behavioral intentions. Trust consists of public willingness, confidence, estimated privacy, and estimated security.

\section{Research model and hypothesis}

The research model in this study is based on findings from relevant prior research on usage and behavioral intentions towards biometric authentication and self-service systems.

Customer perception of the self-service kiosk's functionality represents a utilitarian value, supporting customers in accomplishing their shopping tasks and fulfilling so-called "do-goals" [8], [33]. Functionality is one of the substantial factors within the SQSST model influencing the service quality of self-service technologies [8], [34]. Moreover, functionality comprises the technology's responsiveness, reliability, and ease of use, often regarded as the central point in the design of self-service technology [34]. In other words, when customers can easily operate the selfservice system without any obstacles and help from others, they will intend to use it for the anticipated 
shopping task [21]. According to prior research, functionality contributes to customer perceptions of the service quality of self-service technology and positively affects usage intentions [8], [34].

Perceiving convenience results from a selfservice technology's value through place convenience and time accessibility [8], [35]. In this vein, Collier et al. [35] have identified differences in convenience between public and private self-service technologies. Convenience refers to the fulfillment of expectations such as "when I want" and "where I want" [7], which may result in higher customer satisfaction and usage intention [13]. Research studies on grocery shopping showed that convenience is crucial for self-checkout system quality, resulting in satisfaction with and loyalty to the store [34], [36]. Perceived convenience has been identified as the most common benefit of self-service technologies [37], [38], especially as a factor of self-service technology quality [8], [9], [34], [36]. Thus, prior research, such as Collier and Sherrell [39], could not indicate a direct influence of convenience on usage intentions towards a self-service technology.

Relative advantage is among the core constructs of Rogers' [40] diffusion of innovation theory. It refers to customer perceptions of superior benefits resulting from innovative technology usage rather than an alternative system or traditional face-to-face settings. Even though relative advantage is often compared to perceived usefulness within the TAM [11], [41], prior research emphasizes the differences between the two constructs [42]. While relative advantage involves a person's subjective comparison between an "old" and the new technology, perceived usefulness is the evaluation of benefits without any comparison. According to Meuter et al. [7], advantages generated by self-service technologies refer to time (for instance, in terms of timely independence and duration), ease of use, and access. Prior literature in the domain of retail states that perceived relative advantage is a result of benefits through real-time purchases, especially in highly masculine-oriented cultures (e.g., the United States, Germany, Austria) [11]. These cultures are characterized by "toughness", competitiveness, achievement, and success [43]. Relative advantage is considered a crucial factor for shopping effectiveness when purchasing via a self-service technology and, therefore, contributes to usage and future behavioral intentions [11]. Previous research has also indicated a direct relationship between relative advantage and self-service usage intention [44]. Hence, perceived concerns about customer security when using a selfservice technology might contradict perceptions of relative advantage [45]. Conversely, the latter might also reduce one's perceived risks [46].
While previous research often refers to privacy and security concerns regarding self-service technology usage per se (e.g., [8], [34]), this study highlights security concerns, especially towards biometric authentication processes. Therefore, we first distinguish between privacy and security: privacy concerns define customers' potential loss of control over personal information and data [47]. Regarding self-service technologies, privacy concerns might arise towards the developer or the firm providing the system (e.g., retailer) as well as towards others who are in the same room and might see personal information on the system's display. In contrast, harm to security arising from biometrical authentication refers to the system's failure to recognize or confusion of the correct biometric match, i.e., the "right" person [30]. Jain and Nandakumar [48] refer to those failures as "denial" and "intrusion". Moreover, security threats can also refer to identity theft representing a crucial factor when using biometric authentication systems [49]. Research on usage intentions towards biometric authentication, especially in a shopping context, is still rather sparse. Thus, an investigation of biometric adoption in the tourism sector showed that users had no concerns about biometric technologies [50]. A study on attitude towards biometric identification in banking shows that people are likely to accept the trade-off between security concerns of their biometric information for higher convenience, which may be due to increased comfort with biometric identification (e.g., unlock phones, check-ins at airports) [27]. Consequently, the following hypotheses are considered:

H1: Functionality positively affects usage intentions towards the self-service kiosk.

H2: Convenience positively affects usage intentions towards the self-service kiosk.

H3: Relative advantage positively affects usage intentions towards the self-service kiosk.

H4: Security concerns towards biometric authentication negatively affect usage intentions towards the self-service kiosk.

The considered post-experience behavior in this study refers to positive WOM. Spreading WOM is particularly important to retailers as customers often rely on recommendations from peers, which are, therefore, a key driver of purchase intention [51]. Both determinants of behavioral intentions post technology interaction are commonly used in self-service technology research, such as in [22], [24], [36], [52], [53]. 
H5: Usage intentions positively affect WOM in favor of the self-service kiosk.

H6a-d: Usage intentions mediate the relationship between the independent variables functionality (H6a), convenience (H6b), relative advantage (H6c), and security concerns (H6d) and WOM.

The comprehensive research model is displayed in Figure 1.

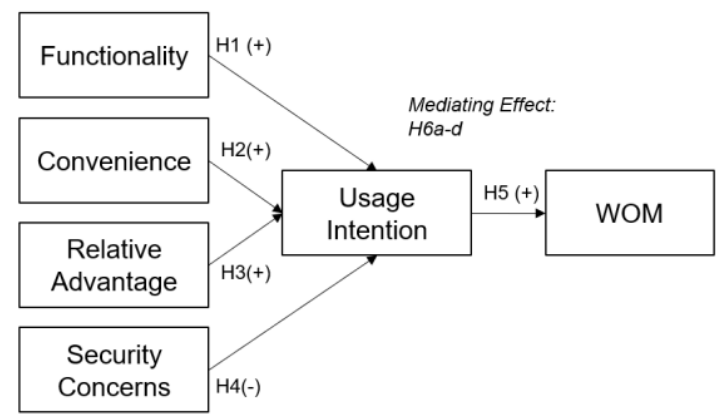

Figure 1: Research model

Note: positive effect $=(+)$; negative effect $(-)$

\section{Methodology}

In this study, we investigate customers' usage intentions towards a self-service kiosk to purchase a new SIM card independent of direct sales employee contact and opening hours (24/7). Purchasing a SIM card requires customer facial authentication, which is typically conducted in physical mobile phone stores or online, where customers need to personally show a valid, government-issued photo ID to sales managers to prove their identity.

\subsection{Data collection}

The study on the self-service kiosk with biometric authentication was tested in a laboratory environment in Austria. Ordered by a bank institute, the kiosk was developed by three Austrian and German companies. Several subsidiaries of the bank have already implemented the self-service kiosk in their entrance areas. The kiosk hardware consists of a 32 " touch screen monitor, a camera for biometric authentication, a scan field for ID cards, a debit card reader with NFC capability, a receipt printer, and a SIM card dispenser.

The task in the study was to purchase a SIM card at the self-service kiosk using personal ID cards and a dummy debit card provided for the study. Participants started by selecting a specific tariff followed by reading and accepting the firm's privacy policy; otherwise, the process would have stopped at this point. Next, customers placed their ID cards on the scan field to let the system retrieve their unique physical traits. Further, the system prompted customers to look into the camera placed to the right of the touchscreen monitor. After successful authentication (i.e., matching the biometric information from the ID card with the real-time camera shot), the customer's personal data (i.e., first name, last name, gender, date of birth, country) appeared on the screen. Next, the system asked the customer to enter an e-mail address in order to activate the SIM card. The final step was to conduct the purchase with the provided dummy debit card. Finally, the self-service kiosk ejected the receipt and the SIM card.

After the purchase procedure, participants completed a quantitative survey about their perception of the self-service kiosk and their behavioral intentions.

\subsection{Sample}

The sample in this study consisted of 28 participants (50\% female, $50 \%$ male) between 21 and 63 years $\left(M_{\text {age }}=37.07, S D_{\text {age }}=12.60\right)$. Most participants were full-time workers $(46 \%)$ or students (43\%). On average, participants' display time (i.e., the summary of self-evaluated mobile phone and notebook usage during the week and on weekends) accounts for $M_{\text {display-time }}=17.45$ hours. In total, 22 participants had prior experience with self-service biometric authentication from check-in or ID-control processes at airports. The data collection procedure adhered strictly to government safety regulations to prevent the spread of COVID-19. Prior to conducting the study's task, participants were informed about the procedure of the study and data storage in verbal and written format. Each participant received a compensation of 10 euros after completing the study.

\subsection{Measures}

The items used to investigate the customers' perception of the self-service kiosk with biometric authentication were derived from prior literature. The four items for functionality were adopted from Ghosh [8], four items for convenience from Wang [13], three items for relative advantage from Meuter et al. [54], and three items for security of biometric authentication from Kanak and Sogukpinar [30]. Three items for usage intentions were derived from Davis and Venkatesh [41], and three items for WOM from Fan et al. [55]. Scales are listed in the Appendix. All items were measured on a 5-point Likert scale from $1=$ completely disagree to $5=$ completely agree. The items were shown to participants in randomized order. 


\section{Results}

This chapter includes the descriptive results followed by those from hypothesis testing using regression analysis and mediation analysis

\subsection{Descriptive results}

The mean scores show a tendency to positive perceptions of the self-service kiosk, especially because of its functionality and convenience. Usage intentions show greater mean values than WOM. Security concerns are perceived as rather low, according to the mean value. Exploratory factor analysis with principal component analysis and varimax rotation technique was employed, proving the validity of the research construct items. The results showed that all items loaded on their respective factors. Reliability analysis using Cronbach's Alpha was conducted to ensure that the items measure the same construct. The values above .70 indicate an acceptable internal consistency for all constructs [56]. Table 1 shows the means, standard deviations, and Cronbach's Alpha values of the scales.

\section{Table 1. Descriptive statistics and Cronbach's $\alpha$}

\begin{tabular}{lccc}
\hline Variables & Mean & S.D. & $\begin{array}{c}\text { Cronbach's } \\
\boldsymbol{\alpha}\end{array}$ \\
\hline Functionality & 4.26 & .65 & .739 \\
\hline Relative advantage & 3.73 & .64 & .778 \\
\hline Convenience & 4.23 & .75 & .790 \\
\hline Security concerns & 2.42 & .95 & .773 \\
\hline Usage intentions & 4.01 & .94 & .922 \\
\hline WOM & 3.64 & .96 & .952 \\
\hline
\end{tabular}

The bivariate correlation analysis revealed that convenience $(r=.70, p<.01)$ and relative advantage $(r=.63, p<.01)$ show significant positive correlations with usage intentions. In contrast, functionality $(r=.29, p>.05)$ and security concerns $(r=.13$, $p>.05)$ do not significantly correlate with usage intentions. WOM $(r=.84, p<.01)$ correlates positively and significantly with usage intentions. As depicted in Table 2, except for security concerns and functionality with usage intentions, the constructs show significant correlations.

\subsection{Hypothesis testing}

Multiple linear regression conducted with SPSS (version 27) was used to test the hypotheses proposed in the research model. The results showed that $76.2 \%$ $(\mathrm{df}=4 ; \mathrm{p}<.001)$ of the variance of usage intentions is explained through the four independent variables.

Table 2. Bivariate correlation analysis results

\begin{tabular}{l|c|c|c|c|c|c}
\hline & 1 & 2 & 3 & 4 & 5 & 6 \\
\hline $\begin{array}{l}\text { Func- } \\
\text { tionality }\end{array}$ & - & & & & & \\
\hline $\begin{array}{l}\text { Conven- } \\
\text { ience }\end{array}$ & $.46^{*}$ & - & & & & \\
\hline $\begin{array}{l}\text { Relative } \\
\text { advantage }\end{array}$ & $.39 *$ & $\begin{array}{l}.57 \\
* *\end{array}$ & - & & & \\
\hline $\begin{array}{l}\text { Security } \\
\text { concerns }\end{array}$ & .01 & .11 & -.04 & - & & \\
\hline $\begin{array}{l}\text { Usage in- } \\
\text { tentions }\end{array}$ & .29 & $\begin{array}{l}.70 \\
* *\end{array}$ & $\begin{array}{l}.63 \\
* *\end{array}$ & .13 & - & \\
\hline WOM & .51 & $\begin{array}{l}.60 \\
* *\end{array}$ & $\begin{array}{l}.67 \\
* *\end{array}$ & -.02 & $\begin{array}{l}.84 \\
* *\end{array}$ & - \\
\hline
\end{tabular}

Multicollinearity can cause instability in regression calculations due to inflated standard errors [57]. Therefore, we calculated the variance inflation factors (VIF) for each independent variable (functionality $<1.53$, relative advantage $<1.29$, convenience $<1.13$, security concerns $<1.65$ ). As the VIF values are below the threshold of 4.0 [58], we can rule out multicollinearity as an influencing factor.

Convenience has a strong positive effect on usage intentions $(b=.65, S E=.22, p<.01)$ supporting $\mathrm{H} 2$. An increase in convenience results in an increase in customer intentions to use the self-service kiosk. Relative advantage also significantly and positively affects usage intentions $(b=.54, S E=.25, p<.05)$, supporting H3. Further, functionality $(b=-.13$, $S E=.22, p=.57)$ and security concerns regarding biometrical authentication $(b=.09, S E=.14, p=.54)$ are not significant, rejecting $\mathrm{H} 1$ and $\mathrm{H} 4$. Therefore, functionality and security concerns towards the selfservice kiosk were not found as factors influencing usage intentions. Linear regression of usage intentions towards WOM $(b=.86, S E=.11, p<.001)$ was shown to have a very strong effect, supporting H5. Table 3 summarizes the results of the hypothesis testing, which are also displayed in Figure 2.

Table 3. Results of hypothesis testing

\begin{tabular}{lcccc}
\hline Variables & $\boldsymbol{b}$ & $\boldsymbol{S E}$ & $\boldsymbol{T}$ & $\boldsymbol{p}$ \\
\hline \multicolumn{4}{c}{ Dependent variable: Usage intention } \\
\hline Functionality & -.129 & .223 & -.580 & .567 \\
\hline Convenience & .654 & .218 & 2.992 & .007 \\
\hline Relative advantage & .540 & .248 & 2.174 & .040 \\
\hline Security concerns & .085 & .135 & .628 & .536 \\
\hline \multicolumn{5}{c}{ Dependent variable: WOM } \\
\hline Usage Intention & .856 & .109 & 7.866 & .000 \\
\hline
\end{tabular}


Additionally, means of all constructs have been examined towards group differences using one-way ANOVAs, leading to no statistically significant results: age (older/younger $M_{\text {age }}$; lowest p-value $=.10$ ), gender (female/male; lowest $\mathrm{p}$-value $=.26$ ), display time (higher/lower $M_{\text {display-time }}$; lowest p-value = .33) .

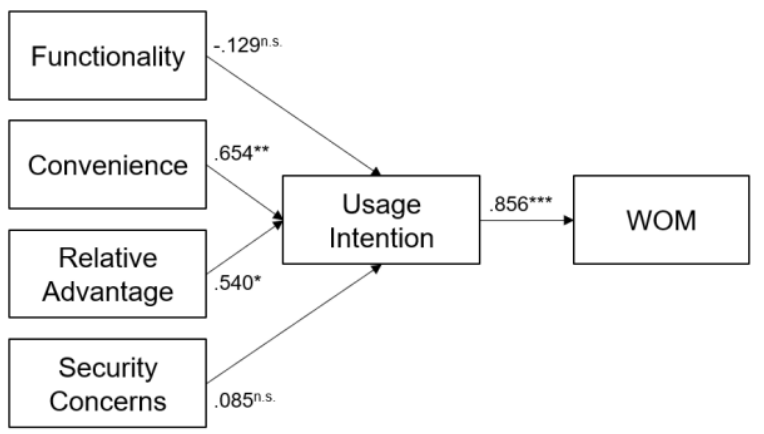

Figure 2. Regression analysis results Note: ${ }^{*} p<.05,{ }^{* \star} p<.01,{ }^{* \star *} p<.001$

\subsection{Mediation analysis}

Mediation Analysis using PROCESS Macro for SPSS (version 3.5) by Hayes [59] was conducted to investigate whether usage intentions fully or partly mediate the relationship between the two statistically significant independent variables and WOM. The mediation analysis (model 4) with 5,000 bootstrap samples did not include zero for the relationship between convenience and WOM $(a b=.738,95 \%$ CI $[.365,1.196])$ as well as between relative advantage and WOM $(a b=.651,95 \%-C I[.297,1.042])$. The results show full mediation of usage intentions for the significant variables and are displayed in Table 4.

Table 4. Mediation analysis results

\begin{tabular}{l|l|l|l|l}
\hline & Effect & $\begin{array}{l}\text { Boot } \\
\boldsymbol{s} \boldsymbol{e}\end{array}$ & $\begin{array}{l}\text { Boot } \\
\text { LLCI }\end{array}$ & $\begin{array}{l}\text { Boot } \\
\text { ULCI }\end{array}$ \\
\hline Functionality & .325 & .214 & -.041 & .819 \\
\hline Convenience & .738 & .209 & .365 & 1.196 \\
\hline $\begin{array}{l}\text { Relative } \\
\text { advantage }\end{array}$ & .651 & .191 & .297 & 1.042 \\
\hline $\begin{array}{l}\text { Security } \\
\text { concerns }\end{array}$ & .114 & .158 & -.180 & .438 \\
\hline
\end{tabular}

An additional Sobel normal theory test [60] supported all the expected mediating effects, as depicted in Table 5. Thus, the mediation analysis results in supporting $\mathrm{H} 6 \mathrm{~b}$ and $\mathrm{H} 6 \mathrm{c}$ while rejecting $\mathrm{H} 6 \mathrm{a}$ and H6d.
Table 5. Sobel test results

\begin{tabular}{l|c|c|c}
\hline & $\mathbf{z}$ & $\mathbf{p}$ & $\begin{array}{c}\text { Mediating } \\
\text { Effect }\end{array}$ \\
\hline Functionality & 1.527 & .127 & no \\
\hline Convenience & 3.681 & .000 & yes \\
\hline Relative advantage & 2.834 & .001 & yes \\
\hline Security concerns & .676 & .500 & no \\
\hline
\end{tabular}

\section{Discussion}

The discussion of our results is divided into three parts. We propose theoretical and managerial implications before stating the study's limitations and proposing future research.

\subsection{Theoretical implications}

The results show that the proposed research model presents good explanatory power $(76.2 \%)$ to predict usage intention towards the self-service kiosks with biometric authentication. Except for functionality (H1) and security concerns (H4), the proposed relationships strongly support the research approach. Hence, the mean values of the insignificant factors indicate a high level of functionality and few security concerns. The first plausible explanations might be associated with the simulated task of purchasing a SIM card in a university lab. This environment might have conveyed a feeling of security to participants. Indeed, we assume that they would have more serious concerns about the violation of their security in a retail environment. The second possible explanation might refer to the fact that most participants were familiar with biometric authentication systems at airports. Therefore, we believe that inexperienced users might perceive greater security concerns. The nonsignificant results of functionality might also depend on prior experience with biometric authentication systems.

Our findings support the expected strong impact of convenience on usage intentions as it is the greatest advantage of self-service technologies [37], [38]. Increasing the level of convenience in terms of place and time accessibility will result in higher intentions to use the self-service kiosk. In contrast to Collier and Sherrell [39], our study confirms a direct positive influence of convenience on usage intention. Even though self-service technologies have been heavily investigated for more than two decades, and biometric authentication emerged as a common process for unlocking the mobile phone or checking in at the airport, the innovation construct of relative advantage plays a crucial role. Customers might be more likely to use the self-service kiosk instead of visiting a 
physical store, which would potentially demand a higher level of effort (e.g., visiting the next city, booking an appointment with a sales employee at the mobile shop beforehand, or waiting in the queue in the store). The results regarding the positive effect of convenience and relative advantage on usage intentions are in line with previous studies on selfservice technologies in the retail sector [11]. These results are independent of customers' age and gender.

\subsection{Managerial implications}

Where, for what products, and to whom can the self-service kiosk with biometric authentication potentially provide the greatest value through convenience and relative advantage? For instance, the presented self-service kiosk might be relevant for young people living in rural areas who have no driver's license yet and like to run errands independently. However, potential customers would profit from a broader product offering. Moreover, the presented self-service kiosk might be highly relevant at airports. For example, transatlantic travelers who arrive in the middle of the night could purchase a SIM card at the self-service kiosk to directly use their phone with a local number and mobile net.

In general, self-service kiosks could be beneficial for customers to increase the availability of products independently of traditional store opening hours while retailers can reduce the number of service employees [7]. In this vein, retailers need to carefully investigate where and for which products the investment in selfservice kiosks could be profitable as customers' usage intention depends on the place and time accessibility (i.e., convenience) [7], [37]. Yet, the presented purchase process is usually conducted in physical retail stores or online, where service employees validate the person's identity. Compared to these purchase processes, the participants in our study confirm the relative advantage of the self-service kiosk [11].

Customers' post-experience behavior of spreading positive WOM might also contribute to the financial success of self-service kiosks. It can be assumed that customers who recommend the technology are convinced to use it themselves [51].

Even though security concerns and functionality showed no significant results in our study, retailers should ensure that the sensitive data of customers' "eigenfaces" is well protected [30] and that the interaction with the self-service kiosk provides responsiveness and reliability (i.e., functionality) [34].

\subsection{Limitations and future research}

The results of this study are subject to further exploration as it has some limitations. First, future studies might replicate our research approach with a higher number of participants to increase the power of the analysis and the generalizability of the results. Second, the sample consisted of users, of which most are familiar with biometric authentication processes at airports. This could represent a bias within the sample. Future studies could compare the factors influencing usage intention towards the self-service kiosk between inexperienced and experienced users (potentially considering negative and positive prior experience). In a similar vein, future research might investigate whether personality traits, such as innovativeness, innovation resistance [61], technology readiness, or computer self-efficacy [62], affect the perception of functionality and security of self-service kiosks with biometric authentication. Third, this laboratory study was conducted in a rural area in Austria. A study replication in cities might shed light on the self-service technology's applicability in urban environments, where the density of retail stores is higher, and customers should be able to access them more easily. Fourth, as the study was conducted only in one country, our findings might vary in geographically different areas [15]. Also, regarding cultural dimensions [63], prior studies identified the functionality of a self-service system to be more important in masculine countries [43]. Even though Austria is considered a masculine culture, functionality was not identified as a significant factor influencing usage intentions. In this regard, a comparative study in a feminine-oriented country would be needed to compare the findings.

In contrast to the self-service kiosk in our study, there are authentication systems that store biometric data on remote databases and compare them with realtime data when initiated [64], such as in the case of cashier-less checkout and access control systems in unmanned retail stores [65], [66]. Consequently, our research model might also apply to these kinds of selfservice technologies with biometric authentication.

\section{Conclusion}

This study aimed to investigate and test factors affecting usage intentions towards a self-service kiosk with biometric authentication and how these intentions influence customers' positive WOM. According to our findings from a laboratory study with 28 participants in Austria, convenience and relative advantage significantly affect customers' intentions to use the proposed system. Further, usage intention fully 
moderates the relationship between these two independent variables and WOM. In contrast to our expectations, functionality and security concerns showed no significant influence.

In conclusion, this research contributes to humancomputer interaction, information systems, and marketing literature by identifying two significant factors (i.e., convenience and relative advantage) affecting usage intentions towards a self-service technology with biometric authentication, further leading to WOM.

\section{Acknowledgements}

This work was funded by the European Union's Horizon 2020 research and innovation program under the Marie SkłodowskaCurie grant agreement No. 765395.

\section{References}

[1] S. Spielberg, Minority Report. USA: 20th Century Fox, DreamWorks Pictures, 2002.

[2] Apple Inc., "The future is here: iPhone X," 2017. https://www.apple.com/newsroom/2017/09/the-futureis-here-iphone- $\mathrm{x} /$ (accessed Jun. 13, 2021).

[3] BusinessWire, "\$15.8 Billion Identity Verification (Non-Biometric and Biometric) Market - Global Forecast to 2025," 2020. https://www.businesswire.com/news/home/202011040 05225/en/15.8-Billion-Identity-Verification-NonBiometric-and-Biometric-Market---Global-Forecastto-2025---ResearchAndMarkets.com (accessed Jun. 13, 2021)

[4] F. Steffens, "Facing up to the new world of border control," Biometric Technol. Today, vol. 9, pp. 8-11, 2020, doi: 10.1016/S0969-4765(20)30123-5.

[5] Z. Zhang, "Technologies Raise the Effectiveness of Airport Security Control," in IEEE 1st International Conference on Civil Aviation Safety and Information Technology (ICCASIT), 2019, pp. 431-434.

[6] L. Xie, W. Shen, and Y. Zheng, "Examining the Effect of Service Experiences on the Attitude towards and Intention on Using Self-Service Technology," Int. Conf. Comput. Sci. Serv. Syst., pp. 2233-2240, 2011.

[7] M. L. Meuter, A. L. Ostrom, R. I. Roundtree, and M. J. Bitner, "Self-service technologies: Understanding customer satisfaction with technology-based service encounters," J. Mark., vol. 64, no. 3, pp. 50-64, 2000, doi: 10.1509/jmkg.64.3.50.18024.

[8] M. Ghosh, "Understanding the relationship of selfservice technology quality with user adoption using SSTQUAL," TQM J., 2020, doi: 10.1108/TQM-122019-0291.

[9] M. V. De Leon, R. P. Atienza, and D. Susilo, "Influence of self-service technology (SST) service quality dimensions as a second-order factor on perceived value and customer satisfaction in a mobile banking application," Cogent Bus. Manag., vol. 7, no. 1, 2020, doi: 10.1080/23311975.2020.1794241.

[10] S. Bulmer, J. Elms, and S. Moore, "Exploring the adoption of self-service checkouts and the associated social obligations of shopping practices," J. Retail. Consum. Serv., vol. 42, no. January, pp. 107-116, 2018, doi: 10.1016/j.jretconser.2018.01.016.

[11] S. K. Roy, M. S. Balaji, and B. Nguyen, "Consumercomputer interaction and in-store smart technology (IST) in the retail industry: the role of motivation, opportunity, and ability," J. Mark. Manag., vol. 36, no. 3-4, pp. 299-333, 2020, doi: 10.1080/0267257X.2020.1736130.

[12] E. Considine and K. Cormican, "Self-service technology adoption: An analysis of customer to technology interactions," Procedia - Procedia Comput. Sci., vol. 100, pp. 103-109, 2016, doi: 10.1016/j.procs.2016.09.129.

[13] M. C. H. Wang, "Determinants and consequences of consumer satisfaction with self-service technology in a retail setting," Manag. Serv. Qual., vol. 22, no. 2, pp. 128-144, 2012, doi: 10.1108/09604521211218945.

[14] H. J. Lee, "Consumer-to-store employee and consumer-to-self-service technology (SST) interactions in a retail setting," Int. J. Retail Distrib. Manag., vol. 43, no. 8, pp. 676-692, 2015, doi: 10.1108/IJRDM-04-2014-0049.

[15] Y. Vakulenko, D. Hellström, and P. Oghazi, "Customer value in self-service kiosks: a systematic literature review," Int. J. Retail Distrib. Manag., vol. 46, no. 5, pp. 507-527, 2018, doi: 10.1108/IJRDM-042017-0084.

[16] N. A. R. Negri, G. M. R. Borille, and V. A. Falcão, "Acceptance of biometric technology in airport checkin," J. Air Transp. Manag., vol. 81, no. February, p. 101720, 2019, doi: 10.1016/j.jairtraman.2019.101720.

[17] A. K. Kaushik and Z. Rahman, "Innovation adoption across self-service banking technologies in india," Int. J. Bank Mark., vol. 33, no. 2, pp. 96-121, 2015, doi: 10.1108/IJBM-01-2014-0006.

[18] J. Klier, M. Klier, A.-L. Müller, and C. Rauch, "Customers Can Do Better! A Case Study of SelfService Kiosk Technologies at the German Federal Employment Agency," Wi, no. 2015, pp. 302-316, 2015.

[19] K. Chang and C. C. Chang, "Library self-service: Predicting user intentions related to self-issue and return systems," Electron. Libr., vol. 27, no. 6, pp. 938-949, 2009, doi: 10.1108/02640470911004048.

[20] P. Holahan, C. V. Brown, C. Abraham, and B. J. Lesselroth, "Integrating self-service kiosks into healthcare delivery organizations," Int. Conf. Inf. Syst. 2011, ICIS 2011, vol. 1, p. 184, 2011.

[21] H. Oh, M. Jeong, S. (Ally) Lee, and R. Warnick, "Attitudinal and Situational Determinants of SelfService Technology Use," J. Hosp. Tour. Res., vol. 40, no. 2, pp. 236-265, 2016, doi: $10.1177 / 1096348013491598$. 
[22] A. Günay and Ç. Erbut, "Eliciting positive user experiences with self-service kiosks: Pursuing possibilities,” Behav. Inf. Technol., vol. 34, no. 1, pp. 81-93, 2015, doi: 10.1080/0144929X.2014.937459.

[23] B. Weijters, D. Rangarajan, T. Falk, and N. Schillewaert, "Determinants and outcomes of customers' use of self-service technology in a retail setting,” J. Serv. Res., vol. 10, no. 1, pp. 3-21, 2007, doi: $10.1177 / 1094670507302990$.

[24] X. Wang and D. Dong, "Use habit, continue use and WOM for SST - Based on e-banking," Proc. - 2012 4th Int. Conf. Multimed. Secur. MINES 2012, pp. 778-781, 2012, doi: 10.1109/MINES.2012.246.

[25] P. F. Hsu, T. K. Nguyen, and J. Y. Huang, "Value cocreation and co-destruction in self-service technology: A customer's perspective," Electron. Commer. Res. Appl., vol. 46, no. 101, p. 101029, 2021, doi: 10.1016/j.elerap.2021.101029.

[26] M. Turk and A. Pentland, "Eigenfaces for recognition," J. Cogn. Neurosci., vol. 3, no. 1, pp. 7186, 1991.

[27] A. M. Mills, "The Future of Identity Management: Understanding Consumer Attitudes Towards Biometric Identification," Int. CON-FIRM Conf. Inf. Resour. Manag., 2019.

[28] A. Mahfouz, T. M. Mahmoud, and A. S. Eldin, "A survey on behavioral biometric authentication on smartphones,” J. Inf. Secur. Appl., vol. 37, pp. 28-37, 2017, doi: 10.1016/j.jisa.2017.10.002.

[29] A. Gelb and J. Clark, "Identification for development: the biometrics revolution," Cent. Glob. Dev. Work. Pap., no. 315, 2013.

[30] A. Kanak and I. Sogukpinar, "BioTAM: A technology acceptance model for biometric authentication systems," IET Biometrics, vol. 6, no. 6, pp. 457-467, 2017, doi: 10.1049/iet-bmt.2016.0148.

[31] I. Berle, "What Is Face Recognition Technology?," in Face Recognition Technology, Face Recog., Cham: Springer, 2020, pp. 9-25.

[32] F. D. Davis, "Perceived Usefulness, Perceived Ease of Use, and User Acceptance of Information Technology," MIS Q., vol. 13, no. 3, pp. 319-340, 1989.

[33] A. Cetto, J. Klier, and M. Klier, "Why should i do it myself? Hedonic and utilitarian motivations of customers' intention to use self-service technologies," 23rd Eur. Conf. Inf. Syst. ECIS 2015, vol. 2015-May, pp. 0-16, 2015.

[34] J. C. Lin and P. Hsieh, "Assessing the Self-service Technology Encounters : Development and Validation of SSTQUAL Scale,” J. Retail., vol. 87, no. 2, pp. 194-206, 2011, doi: 10.1016/j.jretai.2011.02.006.

[35] J. E. Collier, D. L. Sherrell, E. Babakus, and A. B. Horky, "Understanding the differences of public and private self-service technology," J. Serv. Mark., vol. 28, no. 1, pp. 60-70, 2014, doi: 10.1108/JSM-042012-0071.

[36] F. Demirci Orel and A. Kara, "Supermarket selfcheckout service quality, customer satisfaction, and loyalty: Empirical evidence from an emerging market,” J. Retail. Consum. Serv., vol. 21, no. 2, pp. 118-129, 2014, doi: 10.1016/j.jretconser.2013.07.002.

[37] H. Lee, A. Fairhurst, and H. J. Cho, "Gender differences in consumer evaluations of service quality : self-service kiosks in retail," Serv. Ind. J., vol. 33, no. 2, pp. 248-265, 2013, doi: $10.1080 / 02642069.2011 .614346$.

[38] V. Liljander, F. Gillberg, J. Gummerus, and A. van Riel, "Technology readiness and the evaluation and adoption of self-service technologies," J. Retail. Consum. Serv., vol. 13, no. 3, pp. 177-191, 2006, doi: 10.1016/j.jretconser.2005.08.004.

[39] J. E. Collier and D. L. Sherrell, "Examining the influence of control and convenience in a self-service setting," J. Acad. Mark. Sci., vol. 38, pp. 490-509, 2010, doi: 10.1007/s11747-009-0179-4.

[40] E. M. Rogers, Diffusion of Innovations, 5th editio. New York: The Free Press, 2003.

[41] F. D. Davis and V. Venkatesh, "Toward preprototype user acceptance testing of new information systems: Implications for software project management," IEEE Trans. Eng. Manag., vol. 51, no. 1, pp. 31-46, 2004, doi: 10.1109/TEM.2003.822468.

[42] E. Karahanna, M. Ahuja, M. Srite, and J. Galvin, "Individual differences and relative advantage: The case of GSS," Decis. Support Syst., vol. 32, no. 4, pp. 327-341, 2002, doi: 10.1016/S0167-9236(01)00124-5.

[43] M. Blut, C. Wang, and K. Schoefer, "Factors Influencing the Acceptance of Self-Service Technologies: A Meta-Analysis," J. Serv. Res., vol. 19, no. 4, pp. 396-416, 2016, doi: $10.1177 / 1094670516662352$.

[44] M. A. Eastlick et al., "Exploring antecedents of attitude toward co- producing a retail checkout service utilizing a self- service technology," Int. Rev. Retail. Distrib. Consum. Res., vol. 22, no. 4, pp. 337-364, 2012, doi: 10.1080/09593969.2012.690775.

[45] S. M. Fazal-e-Hasan, A. Amrollahi, G. Mortimer, S. Adapa, and M. S. Balaji, "A multi-method approach to examining consumer intentions to use smart retail technology," Comput. Human Behav., vol. 117, no. June 2020, p. 106622, 2021, doi: 10.1016/j.chb.2020.106622.

[46] J. Kim and S. Forsythe, "Adoption of Virtual Try-on technology for online apparel shopping," J. Interact. Mark., vol. 22, no. 2, pp. 45-59, 2008, doi: 10.1002/dir.20113.

[47] J. A. Aloysius, H. Hoehle, and V. Venkatesh, "Exploiting big data for customer and retailer benefits: A study of emerging mobile checkout scenarios," Int. J. Oper. Prod. Manag., vol. 36, no. 4, pp. 467-486, 2016, doi: 10.1108/IJOPM-03-2015-0147.

[48] A. K. Jain and K. Nandakumar, "Biometric Authentication: System Security and User Privacy," IEEE Comput., vol. 45, no. 11, pp. 87-92, 2012.

[49] U. C. Irvine, L. Review, and M. B. Kugler, "From Identification to Identity Theft: Public Perceptions of Biometric Privacy Harms," UC Irvine L. Rev. 10, p. 107, 2019.

[50] H. C. Murphy and D. Rottet, "An exploration of the key hotel processes implicated in biometric adoption," 
Int. J. Contemp. Hosp. Manag., vol. 21, no. 2, pp. 201-212, 2009, doi: 10.1108/09596110910935697.

[51] J. J. Inman and H. Nikolova, "Shopper-Facing Retail Technology: A Retailer Adoption Decision Framework Incorporating Shopper Attitudes and Privacy Concerns,” J. Retail., vol. 93, no. 1, pp. 7-28, 2017, doi: 10.1016/j.jretai.2016.12.006.

[52] K. Mukerjee, "Impact of self-service technologies in retail banking on cross-buying and word-of-mouth," Int. J. Retail Distrib. Manag., vol. 48, no. 5, pp. 485500, 2020, doi: 10.1108/IJRDM-08-2019-0261.

[53] M. L. Meuter, A. L. Ostrom, M. Jo, and R. Roundtree, "The influence of technology anxiety on consumer use and experiences with self-service technologies," J. Bus. Res., vol. 56, pp. 899-906, 2003, doi: 10.1016/S0148-2963(01)00276-4.

[54] M. L. Meuter, M. J. Bitner, A. L. Ostrom, and S. W. Brown, "Choosing among alternative service delivery modes: An investigation of customer trial of selfservice technologies," J. Mark., vol. 69, no. 2, pp. 6183, 2005, doi: 10.1509/jmkg.69.2.61.60759.

[55] X. Fan, N. Ning, and N. Deng, "The impact of the quality of intelligent experience on smart retail engagement," Mark. Intell. Plan., 2020, doi: 10.1108/MIP-09-2019-0439.

[56] J. C. Nunnally and I. H. Bernstein, "Psychometric theory," 1994.

[57] A. Siegel, Practical business statistics. Academic Press, 2016.

[58] R. M. O'brien, "A caution regarding rules of thumb for variance inflation factors," Qual. Quant., vol. 41, no. 5, pp. 673-690, 2007.

[59] A. F. Hayes, Introduction to mediation, moderation, and conditional process analysis: A regression-based approach. Guilford publications, 2017.

[60] M. E. Sobel, "Asymptotic intervals for indirect effects in structural equations models. S. Leinhart," Sociol. Methodol., pp. 290-312, 1982.

[61] S. Heidenreich and T. Kraemer, "InnovationsDoomed to Fail? Investigating Strategies to Overcome Passive Innovation Resistance," J. Prod. Innov. Manag., vol. 33, no. 3, pp. 277-297, 2016, doi: 10.1111/JPIM.12273.

[62] C. L. Chan and C. L. Lin, "Determinants of satisfaction and intention to use self-service technology - Technology readiness and computer selfefficacy," IIH-MSP 2009 - 2009 5th Int. Conf. Intell. Inf. Hiding Multimed. Signal Process., pp. 893-897, 2009, doi: 10.1109/IIH-MSP.2009.115.

[63] G. Hofstede, G. J. Hofstede, and M. Minkov, Kulturer og organisationer. Handelshøjskolens forlag, 2010.

[64] N. Badovinac, "A Multimodal Biometric Authentication (MBA) in Card Payment Systems," in International Conference on Artificial Intelligence: Applications and Innovations (IC-AIAI), 2019, pp. 23-29, doi: 10.1109/IC-AIAI48757.2019.00011.

[65] H. J. Park and Y. Zhang, "Technology readiness and technology paradox of unmanned convenience store users," J. Retail. Consum. Serv., p. 102523, 2021, doi: 10.1016/j.jretconser.2021.102523.
[66] R. A. A. Helmi, M. N. Bin Hishamuddin, A. Jamal, M. G. Md Johar, and L. F. Sim, "Quantum Application: A Smart Cashier-less Shopping Application with Biometric Payment Authentication," in 11th IEEE Symposium on Computer Applications Industrial Electronics (ISCAIE), 2021, pp. 157-162, doi: 10.1109/ISCAIE51753.2021.9431840.

\section{Appendix: Questionnaire Items}

\section{Functionality [8]}

1) I get my SIM card purchase done with the firm's selfservice kiosk in a short time.

2) Using the firm's self-service kiosk requires a little effort. 3) The SIM card purchase process with the firm's selfservice kiosk is clear.

4) I get the SIM card purchase done smoothly with the firm's self-service kiosk.

Convenience [12]

1) Using the self-service kiosk is a convenient way to purchase a SIM card.

2) The self-service kiosk allows me to purchase a SIM card whenever I choose.

3) Using this self-service kiosk makes purchasing a SIM card less time-consuming.

4) The self-service kiosk allows me to save time when purchasing a SIM card.

Relative advantage [54]

1) Using the self-service kiosk improves the process of purchasing a SIM card.

2) Overall, I believe using the self-service kiosk is advantageous for purchasing SIM cards.

3) I believe the self-service kiosk, in general, is the best way to purchase SIM cards.

Security concerns towards biometric authentication [30] 1) The possibility of malicious people entering the system might be a great risk.

2) The possibility of confusing me with others scares me.

3) Possibility of high similarity between me and another person's biometric makes me skeptical.

Usage intentions [41]

1) Assuming I had access to the self-service kiosk, I intend to use it.

2) Given that I had access to the self-service kiosk, I predict that I would use it.

3) If I had to do the SIM card purchase over again, I would still use the self-service kiosk offered by the firm.

Word of mouth (WOM) [55]

1) I will actively recommend this self-service kiosk to my acquaintances.

2) I would be happy to recommend this self-service kiosk to other shoppers.

3) I would actively recommend this self-service kiosk to people who are going to shop. 